\title{
Pyrosequencing scrutiny of bacterial and fungal communities in two Sudanese sorghum-based fermented foods
}

\author{
Mohamed Mutasim Eltayeb ${ }^{1,2^{*}}$ (D), Sara Ahmed Eltigani ${ }^{3}$ and Takeshi Taniguchi ${ }^{1}$
}

\begin{abstract}
Purpose: Several fermented foods are produced from sorghum flour in Africa, especially in the dryland regions where it is the principal crop. It is important to explore the microbial communities in these foods to improve their quality and organoleptic properties. In this study, the bacterial and fungal communities of two popular sorghumbased fermented foods in Sudan (kisra and hulumur) were analyzed, for the first time, using a culture-independent method of next-generation sequencing.

Methods: Fermented doughs for kisra and hulumur production were prepared according to the traditional approach, and then the bacterial and fungal communities were investigated using high-throughput sequencing.

Results: Firmicutes and Proteobacteria phyla were the predominant bacteria in both fermented doughs. At the genus level, the bacterial community was dominated by lactic acid bacteria, primarily Lactobacillus and Pediococcus, which represented $95.7 \%$ and $72 \%$ of the bacterial population in kisra and hulumur, respectively. Next, acetic acid bacteria (Gluconobacter and Acetobacter) were subdominant in hulumur. The fungal community was more heterogeneous among the fermented doughs. Zygomycota (85.5\%) comprised the major phylum in kisra fermented dough, whereas Ascomycota (99.5\%) was predominant in hulumur. The major fungal genera, Rhizopus, Alternaria, Penicillium, Gibberella, Lasiodiplodia, and Aspergillus, were extremely varied between the fermented doughs.

Conclusion: Exploration of kisra and hulumur microbial community structure will expand the knowledge about their microbiota to manipulate the microbial community and improve their quality and organoleptic properties using different microbial recipes.
\end{abstract}

Keywords: Microbial community, Sorghum-fermented doughs, Kisra, Hulumur, Pyrosequencing

\section{Introduction}

Sorghum is the fifth most widely grown cereal crop in the world. More than half of the entire sorghum produced each year is used for human consumption (Beta and Isaak 2016). Its grain forms a staple food for people in several parts of Africa, especially in the dryland regions where it is the principal crop constituting a major

\footnotetext{
* Correspondence: mohamedmutasem@yahoo.com

1 Arid Land Research Center, Tottori University, Tottori 680-0001, Japan ${ }^{2}$ Department of Food Science and Technology, Faculty of Agriculture, University of Khartoum, Shambat, 14413 Khartoum North, Sudan Full list of author information is available at the end of the article
}

source of proteins and calories in the diet of large segments of the population (Belton and Taylor 2004). The people consume sorghum grain as an ingredient of a variety of meals such as bread, pancakes, biscuits, porridge, noodles, beverages, sweets, and snack foods (Ratnavathi and Patil 2014). Several processing techniques are used during the preparation of these foods to improve their quality, organoleptic properties, shelf life, and nutritional values. These include soaking, dehulling, germination, milling, fermentation, boiling, steaming, and cooking (Dirar 1993). Among these techniques, fermentation is the most common process performed in

(c) The Author(s). 2020 Open Access This article is licensed under a Creative Commons Attribution 4.0 International License, which permits use, sharing, adaptation, distribution and reproduction in any medium or format, as long as you give appropriate credit to the original author(s) and the source, provide a link to the Creative Commons licence, and indicate if changes were made. The images or other third party material in this article are included in the article's Creative Commons licence, unless indicated otherwise in a credit line to the material. If material is not included in the article's Creative Commons licence and your intended use is not permitted by statutory regulation or exceeds the permitted use, you will need to obtain permission directly from the copyright holder. To view a copy of this licence, visit http://creativecommons.org/licenses/by/4.0/. 
different methods and in combination with other techniques to prepare meals based on sorghum flour. In this process, the complex organic compounds such as carbohydrates are oxidized into simple substances by microbial enzymes. The produced metabolites enhance the flavor, aroma, and texture of traditionally processed foods, make them edible, enrich them with vitamins and essential amino acids, and preserve the foods from deterioration (Blandino et al. 2003; Franz et al. 2014). Several studies have confirmed the positive impact of fermentation on the shelf life, palatability, in vitro protein digestibility, and nutritional value of sorghum flour in indigenous foods (Elkhalifa et al. 2007; Nkhata et al. 2018; Simwaka et al. 2017).

In Sudan, sorghum grains are consumed as the major ingredient in several fermented foods, including thin pancakes (kisra), thick porridge (aceda), thin fermented gruel (nasha), boiled grain (balela), and beverages such as abreh and hulumur. Kisra is a thin pancake bread prepared by the spreading of fermented sorghum flour on a hot plate. The color, texture, and taste of the product depend primarily on the sorghum variety and fermentation. Hulumur is a syrup prepared by soaking mahogany red to brownish sheets obtained from packing fermented sorghum enriched with the water extracts of dates, hibiscus, and several spices (Dirar 1993).

The microbes involved in the fermentation process of Sudanese fermented foods prepared from sorghum flour have earlier been investigated using culture-dependent methods to isolate and identify the indigenous bacterial and fungal composition. Consequently, several bacteria and fungi have been reported, including Lactobacillus, Pediococcus, Bacillus, Streptococcus, Enterococcus, Erwinia, Enterobacter, Candida, Saccharomyces, Debaryomyces, Penicillium, Aspergillus, Fusarium, and Rhizopus (AbdelGadir and Mohamed 1983; Agab 1985; Hamad et al. 1992, 1997; Mohammed et al. 1991). These microbes are well-known for their useful effects on the organoleptic properties, maturation, and nutritive value of different fermented foods. Moreover, several fermented food bacteria have been used as probiotic microbes to manipulate human microbiota and enhance several biological functions (Enujiugha and Badejo 2015; Melini et al. 2019). However, culture-dependent methods are useful for microbial enumeration, isolation, and characterization only for cultivable microorganisms in specific fermented foods. In addition, most of the isolated microbes belonged to the dominant microbial taxa. Therefore, there is limited information regarding the microbial communities of indigenous Sudanese fermented foods, especially rare bacteria and fungi.

Other culture-independent approaches that have been established to explore the microbial diversity and community include denaturing gradient gel electrophoresis, temporal temperature gel electrophoresis, quantitative real-time polymerase chain reaction, sequencing of $16 \mathrm{~S}$ rRNA gene clone library, and pyrosequencing or nextgeneration sequencing. These culture-independent techniques enhance the monitoring of microbial diversity, structure, and dynamics in naturally fermented foods. In addition to the dominant microbes, these advanced technologies can explore the rarer bacterial and fungal genera to elucidate their possible role in the process of fermentation.

In the present study, the relative abundance and different taxonomic levels of bacterial and fungal communities of two popular Sudanese fermented foods (kisra and hulumur) were investigated using high-throughput sequencing for the first time. The results of this study can be applied to expand the knowledge about the microbiota of kisra and hulumur and manipulate their recipes for large-scale production using an optimized starter culture.

\section{Materials and methods \\ Preparation of kisra and hulumur fermented doughs}

Kisra fermented dough was prepared according to a conventional Sudanese household method as described previously (Hamad et al. 1992), with minor modifications. Sorghum (Tabat variety) was purchased from a local market in Khartoum, Sudan. The flour was mixed with water in a ratio of $1: 2$, and $10 \%$ starter (a previously fermented sorghum sourdough that is exclusively used to initiate sorghum fermentation for kisra making) obtained from a Sudanese household was added. The mixture was covered to avoid contamination and incubated at $37^{\circ} \mathrm{C}$ for $24 \mathrm{~h}$.

Hulumur fermented dough was prepared following a traditional method used by Sudanese households as described previously (Dirar 1993). Sorghum grains (Feterita), hibiscus, tamarind, dates, and spices (ginger, fenugreek seeds, cumin, cardamom, and cinnamon) were purchased from a local market in Khartoum, Sudan. Sorghum grains were divided into two portions. The first portion was immersed in water for $12 \mathrm{~h}$ and then spread on a tray with a cloth. The seeds were kept wet with frequent addition of water for germination. After $72 \mathrm{~h}$, the seeds were dried and ground to a fine flour. The second portion of sorghum grains was ground to a fine flour and cooked to make a thick porridge. Thereafter, the flour of germinated seeds was added to the porridge, mixed well, and then incubated overnight. Hibiscus, tamarind, and dates were soaked overnight and filtered using a metal mesh. The filtrate and the remaining spices were added to the dough and mixed well, and the incubation process was continued overnight to obtain a fermented dough. The fermented dough was mixed well using a sterilized glass rod, and $2 \mathrm{~mL}$ from each 
fermentation bottle of kisra and hulumur was collected and preserved in a freezer for DNA extraction. The fermentation of kisra and hulumur was conducted in triplicate.

\section{Total DNA extraction}

Total DNA was extracted from $0.5 \mathrm{~g}$ of fermented dough using a DNeasy mericon Food Kit (Qiagen Dneasy, Valencia, CA, USA) according to the manufacturer's protocol guidelines. The isolated DNA was eluted in $100 \mu \mathrm{L}$ of elution buffer. The quality and quantity of the extracted DNA were evaluated using a NanoDrop ND1000 spectrophotometer (NanoDrop Technologies, DE, USA). The extracted DNA was preserved at $-20{ }^{\circ} \mathrm{C}$ for further analysis.

\section{S rRNA gene and ITS1 region amplification and sequencing}

To analyze the bacterial and fungal communities, the $16 \mathrm{~S}$ rRNA gene and ITS region were amplified using the primer pair of U519f/U785r (Klindworth et al. 2013) and ITS1F_KYO2/ITS2_KYO2 (Toju et al. 2012), respectively, with six base-specific barcode sequences to distinguish the sample. The PCR was conducted in an Applied Biosystems veriti thermocycler (Thermo Fisher, Scientific, USA) using a reaction mixture containing $10 \mu \mathrm{L}$ of Q5 high-fidelity $2 \times$ master mix (New England Biolabs), $1.0 \mu \mathrm{L}$ each of $10 \mathrm{mM}$ forward and reverse primers, and $1.0 \mu \mathrm{L}(0.9-2.2 \mathrm{ng})$ of DNA. Cycling conditions were as follows: initial denaturation at $98^{\circ} \mathrm{C}$ for $30 \mathrm{~s}$, followed by 35 cycles at $98^{\circ} \mathrm{C}$ for $10 \mathrm{~s}, 50^{\circ} \mathrm{C}$ for bacteria and $55^{\circ} \mathrm{C}$ for fungi for $30 \mathrm{~s}$, and $72^{\circ} \mathrm{C}$ for $1 \mathrm{~min}$, and a final extension step at $72^{\circ} \mathrm{C}$ for $2 \mathrm{~min}$. The amplification was conducted two times for each DNA sample. The quality of the amplified PCR products was verified using $1 \%$ agarose gel electrophoresis, and the two replicates of the PCR were mixed to make one solution for further purification.

According to the manufacturer's instructions, purification was performed using Agencourt AMPure XP (Beckman Coulter Inc., Brea, CA, USA). After purification, the DNA concentration of each sample was measured using the Qubit dsDNA HS Assay Kit (Thermo Fisher Scientific), and equal quantities of DNA from each PCR sample were combined into one tube. Based on the size and quality of DNA in the mixture, which were assessed using the Agilent High Sensitivity DNA Kit and Agilent 2100 Bioanalyzer (Agilent Technologies, Santa Clara, CA, USA), respectively, a dilution library of approximately $10 \mathrm{pM}$ was prepared. Using $25 \mu \mathrm{L}$ of the targeted dilution library, emulsion PCR was conducted using the Ion PGM OT2 400 Kit (Thermo Fisher Scientific, USA) according to the manufacturer's instructions. After recovery of the ion spheres and enrichment, the samples were loaded onto an Ion 318 Chip V2 instrument for sequencing using an Ion Personal Genome Machine (PGM) (Thermo Fisher Scientific, USA). After the analysis, the sequence data with low-quality sequences and polyclonal sequences were removed. The remaining sequences were exported as a FASTQ file from the PGM software. The sequence data of the 16S rRNA gene and ITS region were deposited in the Sequence Read Archive of DNA Data Bank of Japan under the accession number DRA010455. The 6-base pair barcode used for assigning sequences to samples was removed from the sequences, after which sequences shorter than $200 \mathrm{bp}$ were removed. Thereafter, the sequences were clustered into OTUs at $97 \%$ similarity using USEARCH. After processing, taxonomic classification was performed using the RDP classification at an $80 \%$ confidence threshold. The sequence numbers of each OTU from three samples were calculated as a percentage of the total individual sample sequencing, and the averages were presented.

\section{Results}

\section{Summary of sequence information}

A total of six dough samples were prepared to produce two Sudanese fermented foods (kisra and hulumur) and subjected to DNA pyrosequencing to analyze their bacterial and fungal communities. After removing of lowquality sequences (polyclonal sequences, dereplicated, chimeric, and shorter than $200 \mathrm{bp}$ ), a total of 190,236 and 143,649 16S rRNA gene sequences were obtained for kisra and hulumur fermented doughs, respectively. These sequences were further purified by removing the sequences allocated as mitochondria and chloroplast taxonomic groups, and the remaining sequences were used for further analysis. As a result of this step, the total bacterial sequences of hulumur fermented dough dramatically decreased to 61,659 reads, representing $32 \%$ of the initial total sequence number analyzed in hulumur samples. In addition, 53,180 total reads were observed for the fungi analyzed in the kisra samples compared to 11,897 reads observed for hulumur fermented dough. The reading was further clustered at $97 \%$ similarity in 121 and 64 bacterial OTUs and 148 and 69 fungal OTUs for kisra and hulumur fermented dough, respectively (Table 1 and Additional file 2: Table S1 and S2). For evaluating the richness of the bacterial and fungal OTUs of the six samples, rarefaction analysis was performed by plotting the number of OTUs against the sequencing reads. The curves reached the saturation plateau, which indicated that all samples had adequate reads to capture most of the microbial diversity presented in the current bacterial and fungal communities (Fig. 1). However, a comparison of the sample position in the rarefaction curves indicated that the diversity of the bacterial 
Table 1 Summary of sequencing data of kisra and hulumur fermented doughs

\begin{tabular}{|c|c|c|c|c|}
\hline \multirow[t]{2}{*}{ Parameters } & \multicolumn{2}{|l|}{ Bacteria } & \multicolumn{2}{|l|}{ Fungi } \\
\hline & Kisra & Hulumur & Kisra & Hulumur \\
\hline Total sequences & 180,131 & 61,659 & 53,180 & 11,897 \\
\hline Maximum sequences & 64,457 & 22,905 & 29,889 & 4755 \\
\hline Lower sequences & 52,734 & 18,207 & 5675 & 2843 \\
\hline Average & 60,043 & 20,553 & 17,727 & 3966 \\
\hline Number of OTUs & 121 & 64 & 148 & 69 \\
\hline Phylum & 7 & 6 & 4 & 3 \\
\hline Class & 16 & 11 & 13 & 8 \\
\hline Family & 38 & 22 & 33 & 21 \\
\hline Genus & 37 & 16 & 40 & 27 \\
\hline
\end{tabular}

community in kisra was higher than that in hulumur fermented dough.

\section{Bacterial community of kisra and hulumur fermented doughs}

After the OTU table was constructed, all bacterial reads were classified from phylum to species level at 97\% similarity (Additional file 2: Table S1). The reads that could not be assigned to the specific genus level were allocated as unclassified taxa, which together with minor representing groups were presented as others. The relative abundance of the bacteria at phylum and genus levels is summarized in Fig. 2. In the present study, eight phyla were detected in the sorghum fermented doughs, including Firmicutes, Proteobacteria, Bacteroidetes, Acidobacteria, Actinobacteria, Planctomycetes, Verrucomicrobia, and Chloroflexi. Firmicutes was the predominant phylum accounting for $99.3 \%$ and $75.7 \%$ of the total bacterial community in kisra and hulumur fermented doughs, respectively. Proteobacteria was the subdominant phylum with a relative abundance of $24 \%$ in hulumur compared to $0.62 \%$ in kisra fermented dough. The remaining phyla together accounted for only $0.033 \%$ and $0.014 \%$ of the total bacterial community in kisra and hulumur fermented doughs, respectively (Fig. 2). The bacterial reads of kisra fermented dough were further clustered into 16 classes, 38 families, and 37 genera. Meanwhile, 13 classes, 33 families, and 40 genera were observed following the classification of the sequence reads for hulumur fermented dough (Table 1). The major bacterial genera in the sorghum fermented doughs (Lactobacillus, Pediococcus, Gluconobacter, and Acetobacter) varied between the two samples (Fig. 2). In Kisra fermented dough, the dominant genera were Lactobacillus and Pediococcus accounting for $81.7 \%$ and $14.1 \%$, respectively, whereas the bacteria genera in hulumur fermented dough were more diverse, with the most abundant genus being Pediococcus (37.6\%), followed by Lactobacillus (34.9\%), Gluconobacter (17.9\%), and Acetobacter (6.3\%). The sequences of the most abundant genus Lactobacillus were clustered into 25 OTUs (Additional file 2: Table S1). All dominant OTUs that represented $>1 \%$ of the total sequence reads were assigned as Lactobacillus sp. However, other OTUs with fewer sequence reads were assigned as Lactobacillus zeae, Lactobacillus brevis, and Lactobacillus coleohominis. In the Pediococcus genus, OTUs were observed and assigned as Pediococcus sp. However, in the taxonomic groups assigned as others, 28 and 10 genera were observed with trivial relative abundance (Additional file 1: Fig. S1) in kisra and hulumur fermented doughs, respectively.

\section{Fungal community of kisra and hulumur fermented doughs}

We observed that fungal communities were more heterogeneous than bacterial communities. Ascomycota and Zygomycota were detected as the dominant phyla in the sorghum-based fermented doughs. In kisra
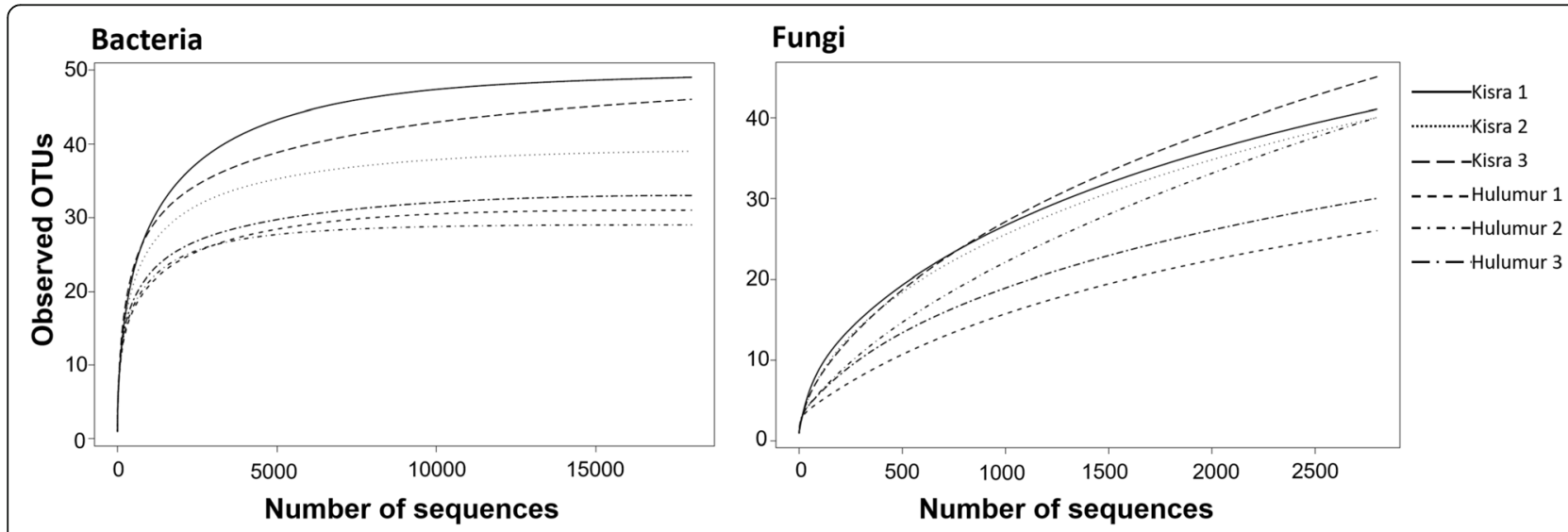

Fig. 1 Rarefaction analysis of observed OTUs at 97\% similarity level 


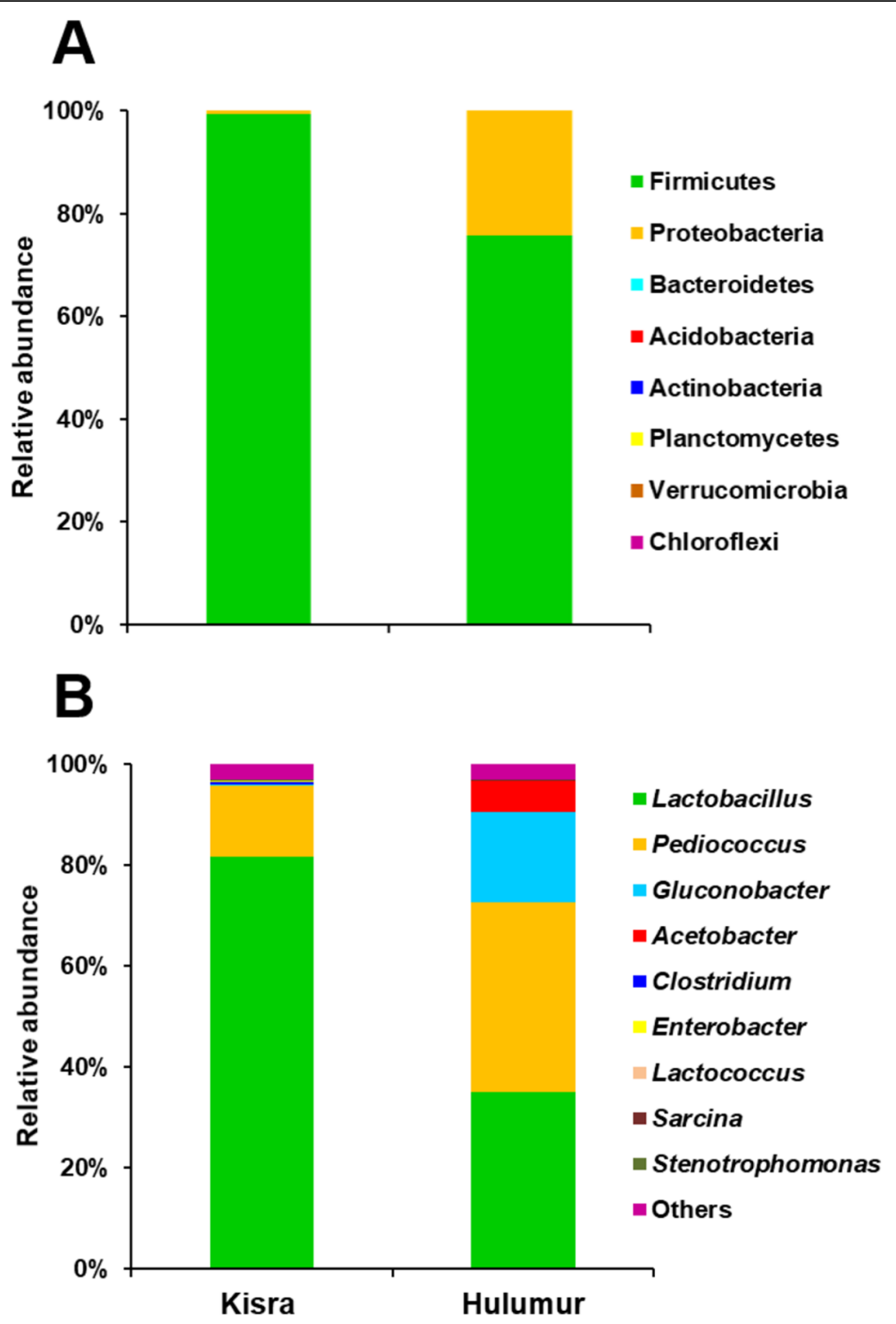

Fig. 2 Relative abundance of the bacterial communities in kisra and hulumur fermented doughs at phylum (a) and genus (b) levels

fermented dough, most of the fungal reads belonged to the phylum Zygomycota (85.46\%), followed by Ascomycota $(9.49 \%)$, Basidiomycota (5.03\%), and Glomeromycota $(0.006 \%)$. However, in hulumur fermented dough, Ascomycota (99.46\%) was the predominant phylum, followed by minor sequences classified as Zygomycota $(0.26 \%)$ and Basidiomycota $(0.28 \%)$. The downstream taxonomic analysis of the fungal reads disclosed 50 genera in the sorghum-based fermented doughs, of which 17 were detected in both fermented doughs (Additional file 2: Table S2). The dominant genera in kisra fermented dough were Rhizopus, Gibberella, Lasiodiplodia, Aspergillus, Candida, and Fusarium, which represented $85.45 \%, 2.54 \%, 1.93 \%, 1.35 \%, 1.16 \%$, and $0.39 \%$ of the fungal community, respectively. These genera were classified primarily as Rhizopus arrhizus, Gibberella fujikuroi, Lasiodiplodia theobromae, Aspergillus cibarius, and Aspergillus flavus. In contrast, Alternaria (71\%) and Penicillium (19.66\%) represented the major genera in hulumur fermented dough, followed by Cochliobolus, Gibberella, Rhizopus, and Aspergillus. Further genera with mild influence on the relative abundance of the fungal community of sorghum-based fermented doughs are listed in Additional file 1: Fig. S2 and Additional file 2: Table S2. These least-detected sequences encompassed 30 and 19 genera in kisra and hulumur fermented doughs, respectively, of which some yeasts (Rhodotorula and Cryptococcus) and fungi (Mortierella and Mucor) with biotechnological potential were observed with minor sequence reads. 


\section{Discussion}

Numerous fermented foods are conventionally prepared from sorghum flour in different parts of Sudan to improve the organoleptic taste, nutritional values, and shelf life of the final products. The microbes mediating these processes have been investigated thoroughly using culture-depended methods (Agab 1985; Hamad et al. 1992, 1997; Mohammed et al. 1991). However, there is a lack of information about the entire microbial communities and their accumulated roles in the fermentation process. Pyrosequencing analysis can provide a detailed description of the microbial community of fermented foods, which also helps in investigating the potential microbes and characterizing unexplored beneficial microbiota (Yang et al. 2016).

In the present study, the bacterial and fungal communities of two Sudanese sorghum-based fermented doughs, kisra and hulumur, were analyzed using highthroughput sequencing technologies. The sequencing data provided sufficient reads for bacterial and fungal communities (Table 1). As illustrated in the diversity rarefaction curve (Fig. 1), all samples reached saturation level, indicating that all phylotypes present in the bacterial and fungal communities were detected and the results could be used to elucidate the microbial diversity of the analyzed samples.

The results showed that the majority of bacterial communities in kisra and hulumur fermented doughs belonged to Firmicutes and Proteobacteria (Fig. 2). These results align with previous studies (Agab 1985; Hamad et al. 1997; Mohammed et al. 1991) conducted using culture-dependent methods in which all isolated microbes belonged to Firmicutes and Proteobacteria. In general, Firmicutes and Proteobacteria are the most dominant phyla in most of the fermented cereals, beverages, and vegetables in different parts of the world (Diaz et al. 2019; Laureys and De Vuyst 2014; Zabat et al. 2018).

At the genera level, Lactobacillus, Pediococcus, Clostridium, Enterobacter, and Lactococcus were the most dominant in kisra fermented dough compared to Lactobacillus, Pediococcus, Gluconobacter, and Acetobacter in hulumur fermented dough (Fig. 2). These differences in the bacterial communities between kisra and hulumur fermented doughs might be attributed to the numerous raw materials used in the preparation of hulumur and the process applied for preparation, including germination, soaking, and cooking. Lactic acid bacteria (Lactobacillus and Pediococcus) are the most abundant group in several African fermented foods prepared from sorghum flour (Diaz et al. 2019), which is consistent with our findings. However, the most dominant OTUs within the Lactobacillus and Pediococcus genera could not be classified to species level due to the short length of the $16 \mathrm{~S}$ rRNA gene sequences. However, the dominant species in kisra fermented dough were investigated using culture-dependent methods and reported as Lactobacillus fermentum, Lactobacillus reuteri (Hamad et al. 1997), Lactobacillus confuses, L. brevis, Pediococcus pentosaceus, and Enterococcus faecium (Mohammed et al. 1991). A study conducted by Abdel Rahman et al. (2010) reported that $P$. pentosaceus was dominant over Lactobacillus coprophilus, Lactobacillus cellobiosus, and L. brevis. Moreover, the superiority of specific Lactobacillus species such as Lactobacillus delbrueckii, L. brevis, Lactobacillus plantarum, Lactobacillus lactis, and L. fermentum was confirmed in various sorghum-based fermented foods in Africa (Adebo 2020). Several strains belonging to some of these Lactobacillus species are well-known for their probiotic properties in fermented foods and human health. These include the elimination of pathogenic bacterial growth, production of bacteriocin, improving flavors, and improving the nutritive values of cereal products with amino acids (Xu et al. 2020).

The acetic acid bacterial group (Acetobacter and Gluconobacter) was subdominant in hulumur fermented dough. Together with Lactobacillus, Acetobacter was found to dominate the bacterial community of several African fermented foods such as Ogi, maize dough in Ghana, Kwerionik, and Ugandan ghee (Diaz et al. 2019). Acetic acid bacteria are known to play pivotal roles in several fermented foods. They are important microbes in the food industry because of their ability to oxidize various types of sugars and alcohols into organic acids as end products during the fermentation process (Sengun and Karabiyikli 2011).

The results of the bacterial community observed in our study were comparable with those reported in several studies conducted using culture-dependent methods, in which Lactobacillus, Pediococcus, and Enterococcus were found to be the dominant genera in kisra fermented dough (Abdel Rahman et al. 2010; AbdelGadir and Mohamed 1983; Hamad et al. 1997; Mohammed et al. 1991). However, the bacterial genera observed in hulumur fermented dough in the present study varied from those reported earlier (Agab 1985). Five of the seven bacterial genera (Bacillus, Streptococcus, Micrococcus, Staphylococcus, Aerococcus, Corynebacterium, and Actinobacillus) isolated during different stages of fermentation were not detected in the current analysis (Fig. 2 and Additional file 1: Fig. S1). Although pyrosequencing results are more accurate, several factors such as the microbial load of the raw materials, fermentation conditions, and hulumur preparation techniques, which differ between areas, might affect the microbial community of fermented foods. Moreover, the present study focused on the final stage of the fermentation process. Therefore, other bacterial genera might play essential roles in the early stage, or they could not resist a lower $\mathrm{pH}$ at the end of the fermentation process. 
Most of the sequencing reads of the potentially pathogenic genus Clostridium in kisra fermented dough were classified as Clostridium butyricum $(0.6 \%$ of the total reads). Strains belonging to this species have been used as a probiotic bacterium in several food products, such as milk and cheese, and several studies have confirmed their beneficial effects in human gut microbiota. For instance, a study reported that feeding rabbits with a diet containing $C$. butyricum significantly increased their growth rate by enhancing the immune function and the improvement of intestinal microbiota (Liu et al. 2019). However, the detection of a few reads belonging to the pathogenic species Clostridium perfringens $(>0.01 \%$ of the total bacterial reads) in kisra fermented dough might be attributed to the uncontrolled conditions applied to prepare the starter used in this study, which was provided by households. Therefore, using recognized starter cultures to initiate the fermentation process might eliminate the incidence of such pathogenic microbes.

The fungal communities in kisra and hulumur fermented doughs were dominated by Zygomycota and Ascomycota, respectively (Fig. 3). This result was consistent with previous results indicating that all the isolated fungi from kisra and hulumur fermented doughs belonged to those major phyla. Ascomycota and Zygomycota are the largest fungal phyla, reported to be dominant in diverse fermented foods such as Colombian fermented coffee beans (de Oliveira Junqueira et al. 2019), fermented bean curd (Wan et al. 2020), and Chinese fermented pepper (Zhao et al. 2016).

At the genera level, the fungal community succession revealed that Rhizopus was the predominant genus in kisra fermented dough, whereas Alternaria and Penicillium were the primary fungal microbiota in hulumur fermented dough (Fig. 3). Several fungal genera were isolated in the currently investigated Sudanese sorghumbased fermented foods, and included Candida intermedia, Debaryomyces hansenii, Aspergillus sp., Penicillium sp., Fusarium sp., and Rhizopus sp. (Agab 1985; Hamad et al. 1992, 1997; Mohammed et al. 1991). Except for Debaryomyces, all these fungal genera were detected in the current study with various relative abundances (Fig. 3 and Additional file 1: Fig. S2).

The most abundant genus Rhizopus, found in kisra fermented dough, is a group of filamentous fungi that contains several potentially economically important species used in fermented foods and other industrial applications. Rhizopus species are used in biotechnology to produce several important enzymes and metabolites such as cellulase, glucoamylase, proteinase, lipase, pectinase, amylase, lactic acid, fumaric acid, and biotin (Ghosh and Ray 2011; Liu et al. 2016). The most dominant species in kisra fermented dough, $R$. arrhizus (also known as Rhizopus oryzae), was reported to be a dominant species in several cereal-based fermented foods, including barley tempeh (Feng et al. 2005), fermented rice (Blandino et al. 2003), and weaning foods prepared from pearl millet, sorghum, groundnut, and cowpea (Badau et al. 2006). In addition, an earlier study indicated an antifungal effect of Rhizopus volatile metabolites during the fermentation process, which might explain the decreased rates of other fungal genera in the fermented dough (Lanciotti and Guerzoni 1993).

In a previous study, Alternaria, a predominant genus in the currently investigated Hulumur fermented dough (Fig. 3), was isolated as a subdominant fungus during the early stages of the fermentation of three sorghum varieties used in kisra production (Abdel Rahman et al. 2010). The dominancy of Alternaria in the present study might be due to its high level in sorghum grains or its increment during the germination process of sorghum. Although several Alternaria species have been reported to be mycotoxin producers, an earlier study mentioned that most of these toxins were completely degraded during dry baking (Siegel et al. 2010). In addition, Alternaria was found to be a source of compounds with potential properties such as antioxidant, antimicrobial, antidiabetic, and antitumor activities (Eram et al. 2018). The subdominant fungi Penicillium species are wellknown for their role in fermented foods and industrial applications. They have been previously isolated from different cereal-based fermented foods such as Injera, Busaa, Chicha, Rabdi, Kenkey, Minchin, and Ogi (Blandino et al. 2003).

On the other hand, complex and diverse bacterial and fungal genera comprised the least detected group in fermented doughs. Except three bacterial genera (Bacillus, Streptococcus, and Flavobacterium) (Agab 1985), none of these bacteria and fungi have been reported in kisra and hulumur fermented doughs. However, some of these microbial group members exhibited numerous fermentation and biotechnological capabilities, such as Bacillus, Streptococcus, Rhodotorula, Cryptococcus, and Mortierella (Kimura and Yokoyama 2019; Markakiou et al. 2020; Rodrigues et al. 2019; Parka et al. 2017; Goyzueta et al. 2020). Therefore, the diversity of this group and their ability to produce several organic compounds that might affect the organoleptic properties of fermented doughs require further research to delineate their impact on the process of fermentation.

\section{Conclusions}

Although the microbes present in Sudanese sorghumbased fermented foods have been elucidated using culture-dependent methods, these methods have several limitations that can be overcome using pyrosequencing technologies. In the present study, the bacterial and fungal communities of kisra and hulumur fermented doughs 


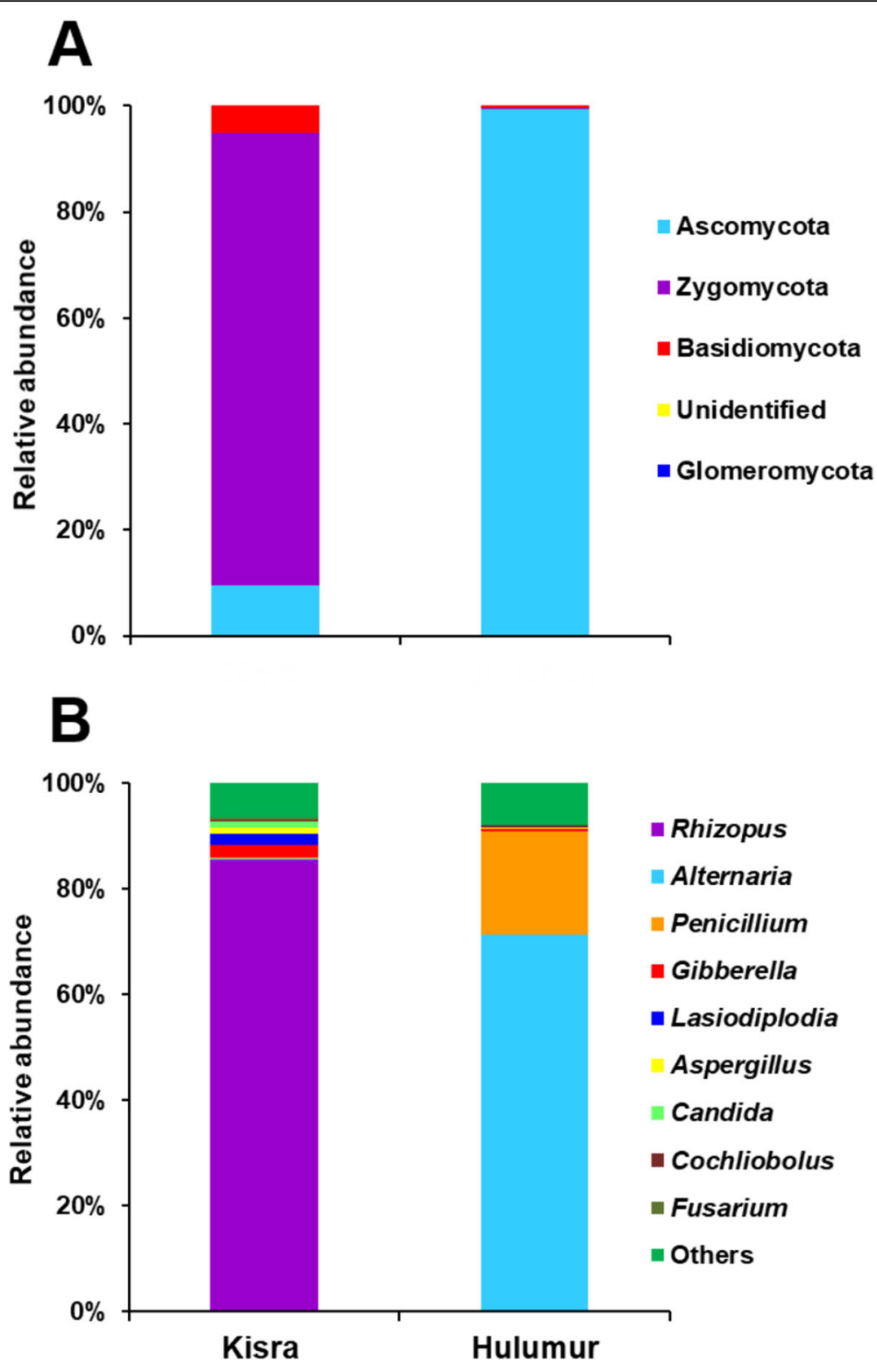

Fig. 3 Fungal community composition of kisra and hulumur fermented doughs at phylum (a) and genus (b) levels

were analyzed using pyrosequencing for the first time. The results demonstrated different microbial community structures between the two fermented foods. Lactobacillus, Pediococcus, and Rhizopus were predominant in kisra fermented dough, whereas Pediococcus, Lactobacillus, Alternaria, and Penicillium were predominant in hulumur fermented dough. These results support the presence of previously isolated microbes. However, several microbes identified in this study were not detected in the previous microbial analysis of kisra and hulumur fermented doughs. Further studies are required to explore the function of the detected microbes through the fermentation process, which would help in manipulating the microbial community of the starter to improve the quality, safety, and organoleptic properties of kisra and hulumur, as well as to enhance the large scale production.

\section{Supplementary information}

Supplementary information accompanies this paper at https://doi.org/10. 1186/s13213-020-01595-4.

Additional file 1: Fig. S1. Bacterial groups with relative prevalence < $0.03 \%$ in Kisra (A) and Hulumur (B) fermented doughs. Fig. S2. Fungal groups with relative prevalence $<0.3 \%$ in Kisra (A) and Hulumur (B) fermented doughs. 
Additional file 2: Table S1. Relative abundance (\%) of bacterial OTUs of Kisra and Hulumur fermented doughs. Table S2. Relative abundance (\%) of fungal OTUs of Kisra and Hulumur fermented doughs.

\section{Acknowledgements}

This study was supported by the Arid Land Research Center, Tottori University, Japan. We would like to acknowledge Mrs. Aziza Sabri Medhat for her technical support in the preparation of hulumur fermented dough. The authors would like to thank Enago (www.enago.jp) and Mr. Sean Otani for the English language review.

\section{Authors' contributions}

The authors read and approved the final manuscript.

\section{Ethics approval and consent to participate}

This article does not contain any studies with human participants or laboratory animals.

\section{Consent for publication}

N/A

\section{Competing interests}

The authors declare that they have no conflict of interest.

\section{Author details}

'Arid Land Research Center, Tottori University, Tottori 680-0001, Japan. ${ }^{2}$ Department of Food Science and Technology, Faculty of Agriculture, University of Khartoum, Shambat, 14413 Khartoum North, Sudan. ${ }^{3}$ The United Graduate School of Agricultural Sciences, Tottori University, Koyama, Tottori 680-8553, Japan.

Received: 13 May 2020 Accepted: 19 August 2020

Published online: 04 September 2020

\section{References}

Abdel Rahman IE, Hamad S, Osman M, Dirar HA (2010) Characterization and distribution of microorganisms associated with kisra bread preparation from three sorghum varieties in Sudan. Curr Res Bacteriol 3:138-147. https://doi. org/10.3923/crb.2010.138.147

AbdelGadir MA, Mohamed M (1983) Sudanese kisra. In: Steinkraus K (ed) Handbook of indigenous fermented foods, Microbiology Series 9. Marcel Dekker Inc., New York, pp 175-179

Adebo OA (2020) African sorghum-based fermented foods: past, current and future prospects. Nutrients 12:111. https://doi.org/10.3390/nu12041111

Agab MA (1985) Fermented food products "Hulu Mur" drink made from Sorghum bicolor. Food Microbiol 2:147-155

Badau MH, Jideani IA, Nkama I (2006) Production, acceptability and microbiological evaluation of weaning food formulations. J Trop Pediatr 52: 166-172. https://doi.org/10.1093/tropej/fmi079

Belton PS, Taylor JR (2004) Sorghum and millets: protein sources for Africa. Trends Food Sci Technol 15:94-98. https://doi.org/10.1016/j.tifs.2003.09.002

Beta T, Isaak C (2016) Grain production and consumption: Overview. In: Wrigley C, Corke H, Seetharaman K, Faubion J (eds) Encyclopedia of food grains, vol 1. Elsevier, Oxford, pp 349-358

Blandino A, Al-Aseeri ME, Pandiella SS, Cantero D, Webb C (2003) Cereal-based fermented foods and beverages. Food Res Int 36:527-543. https://doi.org/10. 1016/S0963-9969(03)00009-7

de Oliveira Junqueira AC, de Melo Pereira GV, Coral Medina JD, Alvear MCR Rosero R, de Carvalho Neto DP, Enríquez HG, Soccol CR (2019) First description of bacterial and fungal communities in Colombian coffee beans fermentation analysed using Illumina-based amplicon sequencing. Sci Rep 9: 8794. https://doi.org/10.1038/s41598-019-45002-8

Diaz M, Kellingray L, Akinyemi N, Adefiranye OO, Olaonipekun AB, Bayili GR, Ibezim J, du Plessis AS, Houngbédji M, Kamya D, Mukisa IM, Mulaw G, Manthi Josiah S, Onyango Chienjo W, Atter A, Agbemafle E, Annan T, Bernice Ackah N, Buys EM et al (2019) Comparison of the microbial composition of African fermented foods using amplicon sequencing. Sci Rep 9:13863. https://doi. org/10.1038/s41598-019-50190-4

Dirar $\mathrm{H}$ (1993) The indigenous fermented foods of the Sudan, a study in African food and nutrition. CAB International, Wallingford
Elkhalifa AO, Ali AM, El Tinay AH (2007) Fermented sorghum foods of Sudan - a review. J Food Sci Technol 44:343-349

Enujiugha VN, Badejo AA (2015) Probiotic potentials of cereal-based beverages. Crit Rev Food Sci Nutr 57:790-804. https://doi.org/10.1080/10408398.2014. 930018

Eram D, Arthikala M-K, Melappa G, Santoyo G (2018) Alternaria species: endophytic fungi as alternative sources of bioactive compounds. Ital J Mycol 47:40-54. https://doi.org/10.6092/issn.2531-7342/8468

Feng XM, Eriksson ARB, Schnürer J (2005) Growth of lactic acid bacteria and Rhizopus oligosporus during barley tempeh fermentation. Int J Food Microbiol 104:249-256. https://doi.org/10.1016/j.jfoodmicro.2005.03.005

Franz CMAP, Huch M, Mathara JM, Abriouel H, Benomar N, Reid G, Galvez A, Holzapfel WH (2014) African fermented foods and probiotics. Int J Food Microbiol 190:84-96. https://doi.org/10.1016/j.i.jfoodmicro.2014.08.033

Ghosh B, Ray RR (2011) Current commercial perspective of Rhizopus oryzae: a review. J Appl Sci 11:2470-2486. https://doi.org/10.3923/jas.2011.2470.2486

Goyzueta MLD, Noseda MD, Bonatto SJR, de Freitas RA, de Carvalho JC, Soccol CR (2020) Production, characterization, and biological activity of a chitin-like EPS produced by Mortierella alpina under submerged fermentation. Carbohydr. Polym. 247:116716. https://doi.org/10.1016/j.carbpol.2020.116716

Hamad SH, Böcker G, Vogel RF, Hammes WP (1992) Microbiological and chemical analysis of fermented sorghum dough for kisra production. Appl Microbiol Biotechnol 37:728-731. https://doi.org/10.1007/BF00174836

Hamad SH, Dieng MC, Ehrmann MA, Vogel RF (1997) Characterization of the bacterial flora of Sudanese sorghum flour and sorghum sourdough. J Appl Microbiol 83:764-770. https://doi.org/10.1046/j.1365-2672.1997.00310.x

Kimura K, Yokoyama S (2019) Trends in the application of Bacillus in fermented foods. Curr Opin Biotech 56C:36-42. https://doi.org/10.1016/j.copbio.2018.09. 001

Klindworth A, Pruesse E, Schweer T, Peplies J, Quast C, Horn M, Glöckner FO (2013) Evaluation of general 16S ribosomal RNA gene PCR primers for classical and next-generation sequencing-based diversity studies. Nucleic Acids Res 41:e1-e1. https://doi.org/10.1093/nar/gks808

Lanciotti R, Guerzoni ME (1993) Competitive inhibition of Aspergillus flavus by volatile metabolites of Rhizopus arrhizus. Food Microbiol 10:367-377. https:// doi.org/10.1006/fmic.1993.1043

Laureys D, De Vuyst L (2014) Microbial species diversity, community dynamics, and metabolite kinetics of water Kefir fermentation. Appl Environ Microbiol 80:2564-2572. https://doi.org/10.1128/AEM.03978-13

Liu H, Ma J, Wang M, Wang W, Deng L, Nie K, Yue X, Wang F, Tan T (2016) Food waste fermentation to fumaric acid by Rhizopus arrhizus RH7-13. Appl Biochem Biotechnol 180:1524-1533. https://doi.org/10.1007/s12010-0162184-7

Liu L, Zeng D, Yang M, Wen B, Lai J, Zhou Y, Sun H, Xiong L, Wang J, Lin Y, Pan K, Jing B, Wang P, Ni X (2019) Probiotic Clostridium butyricum improves the growth performance, immune function, and gut microbiota of weaning rex rabbits. Probiotics Antimicrob Proteins 11:1278-1292. https://doi.org/10.1007/ s12602-018-9476-x

Markakiou S, Gaspar P, Johansen E, Zeidan AA, Neves AR (2020) Harnessing the metabolic potential of Streptococcus thermophilus for new biotechnological applications. Curr Opin Biotech 61:142-152. https://doi.org/10.1016/j.copbio. 2019.12.019

Melini F, Melini V, Luziatelli F, Ficca AG, Ruzzi M (2019) Health-promoting components in fermented foods: an up-to-date systematic review. Nutrients 11:1189. https://doi.org/10.3390/nu11051189

Mohammed SI, Steenson LR, Kirleis AW (1991) Isolation and characterization of microorganisms associated with the traditional sorghum fermentation for production of Sudanese kisra. Appl Environ Microbiol 57:2529-2533. https:// doi.org/10.1128/aem.57.9.2529-2533.1991

Nkhata SG, Ayua E, Kamau EH, Shingiro JB (2018) Fermentation and germination improve nutritional value of cereals and legumes through activation of endogenous enzymes. Food Sci Nutr 6:2446-2458. https://doi.org/10.1002/ fsn3.846

Parka GW, Chang HN, Jung K, Seo C, Kimb Y, Choi JH, Wooc HC, Hwang (2017) Production of microbial lipid by Cryptococcus curvatus on rice straw hydrolysates. Process Biochem 56:147-153. https://doi.org/10.1016/j.procbio. 2017.02.020

Ratnavathi CV, Patil JV (2014) Sorghum utilization as food. J Nutr Food Sci 4:1-8. https://doi.org/10.4172/2155-9600.1000247

Rodrigues TVD, Amore TD, Teixeira EC, Burkert JFD (2019) Carotenoid production by Rhodotorula mucilaginosa in batch and fed-batch fermentation using 
agroindustrial byproducts. Food Technol Biotechnol 57:388-398. https://doi. org/10.17113/ftb.57.03.19.6068

Sengun IY, Karabiyikli S (2011) Importance of acetic acid bacteria in food industry. Food Control 22:647-656. https://doi.org/10.1016/j.foodcont.2010.11.008

Siegel D, Feist M, Proske M, Koch M, Nehls I (2010) Degradation of the Alternaria mycotoxins alternariol, alternariol monomethyl ether, and altenuene upon bread baking. J Agric Food Chem 58:9622-9630. https://doi.org/10.1021/ jf102156w

Simwaka JE, Chamba MVM, Huiming Z, Masamba KG, Luo Y (2017) Effect of fermentation on physicochemical and antinutritional factors of complementary foods from millet, sorghum, pumpkin and amaranth seed flours. Int Food Res J 24:1869-1879

Toju H, Tanabe AS, Yamamoto S, Sato H (2012) High-coverage ITS primers for the DNA-based identification of Ascomycetes and Basidiomycetes in environmental samples. PLoS One 7:e40863. https://doi.org/10.1371/journal. pone.0040863

Wan H, Liu T, Su C, Ji X, Wang L, Zhao Y, Wang Z (2020) Evaluation of bacterial and fungal communities during the fermentation of Baixi sufu, a traditional spicy fermented bean curd. J Sci Food Agric 100:1448-1457. https://doi.org/ $10.1002 /$ jsfa. 10151

Xu Y, Zhou T, Tang H, Li X, Chen Y, Zhang L, Zhang J (2020) Probiotic potential and amylolytic properties of lactic acid bacteria isolated from Chinese fermented cereal foods. Food Control 111:107057. https://doi.org/10.1016/j. foodcont.2019.107057

Yang L, Yang H, Tu Z, Wang X (2016) High-throughput sequencing of microbial community diversity and dynamics during douchi fermentation. PLoS One 11(12):e0168166. https://doi.org/10.1371/journal.pone.0168166

Zabat M, Sano W, Wurster J, Cabral D, Belenky P (2018) Microbial community analysis of Sauerkraut fermentation reveals a stable and rapidly established community. Foods 7:77. https://doi.org/10.3390/foods7050077

Zhao L, Li Y, Jiang L, Deng F (2016) Determination of fungal community diversity in fresh and traditional Chinese fermented pepper by pyrosequencing. FEMS Microbiol Lett 363:fnw273. https://doi.org/10.1093/femsle/fnw273

\section{Publisher's Note}

Springer Nature remains neutral with regard to jurisdictional claims in published maps and institutional affiliations.

Ready to submit your research? Choose BMC and benefit from:

- fast, convenient online submission

- thorough peer review by experienced researchers in your field

- rapid publication on acceptance

- support for research data, including large and complex data types

- gold Open Access which fosters wider collaboration and increased citations

- maximum visibility for your research: over $100 \mathrm{M}$ website views per year

At $\mathrm{BMC}$, research is always in progress.

Learn more biomedcentral.com/submissions 